\title{
Charcot-Marie-Tooth disease type 2P
}

INSERM

\section{Source}

INSERM. (1999). Orphanet: an online rare disease and orphan drug data base. CharcotMarie-Tooth disease type 2P. ORPHA:300319

Charcot-Marie-T ooth disease type $2 \mathrm{P}$ is a rare, genetic, axonal hereditary motor and sensory neuropathy disorder characterized by adulthood-onset of slowly progressive, occasionally asymmetrical, distal muscle weakness and atrophy (predominantly in the lower limbs), pan-modal sensory loss, muscle cramping in extremities and/or trunk, pes cavus and absent or reduced deep tendon reflexes. Gait anomalies and variable autonomic disturbances, such as erectile dysfunction and urinary urgency, may be associated. 